\title{
EFEITO DA ADIÇÃO DE DIFERENTES FONTES DE CÁLCIO NO MOVIMENTO DE CÁTIONS EM COLUNAS DE SOLO.
}

\author{
I.C. de MARIA; R. ROSSETTO; E.J. AMBROSANO; O.M. de CASTRO \\ Bolsista do CNPq e Pesquisador Cientffico-IAC, Av. Barão de Itapura, 1481 - CEP: 13020-902-Campinas,SP. \\ A.M.L. NEPTUNE (in memorian) \\ Prof. Titular do Dep. de Ciência do Solo da ESALQ/USP - Caixa Postal, 9 - CEP: 13418-900-Piracicaba,SP.
}

\begin{abstract}
RESUMO: No estudo realizado em colunas de solo montadas em laboratório, procurou-se avaliar o movimento do cálcio, e de outros cátions, após aplicação de calcário agrícola, gesso, calcário calcinado e uma mistura de calcário agrícola e gesso, comparados com um tratamento testemunha, em dois latossolos vermelho escuros de texturas diferentes: média e argilosa. Utilizaram-se colunas de $P V C$, com $5 \mathrm{~cm}$ de diâmetro e $45 \mathrm{~cm}$ de altura, e aplicaram-se em cada coluna 1,8 hitros de água, parcelados em quatro vezes. Determinaram-se os cátions trocáveis presentes na água percolada e, no final do experimento, em cinco profundidades de cada solo. Os resultados mostraram que nos tratamentos gesso e calcário mais gesso as quantidades de $\mathrm{Ca}^{2+}, \mathrm{Mg}^{2+}, \mathrm{K}^{+}$.e $\mathrm{Al}^{3+}$ na solução percolada foram maiores, enquanto que os tratamentos calcário agrícola e calcário calcinado não promoveram perdas significativas de cátions. As maiores perdas ocorreram na primeira percolação no solo de textura média e na segunda no solo de textura argilosa. $\mathrm{O}$ gesso não modificou o pII dos solos, mas reduziu teores de bases no solo argiloso, enquanto que os calcários corrigiram o solo apenas próximo à camada de incorporação.
\end{abstract}

Descritores: lixiviação, cálcio, magnésio, potássio, alumínio, gesso, calcário.

\section{EFFECT OF SEVERAL CALCIUM SOURCES ON CATION LEACIIING USING SOIL COLUMNS.}

\begin{abstract}
ABSTRAC'T: Soil columns under controlled conditions were used to determine the movement of calcium and other cations after the application of lime, calcium oxide, gypsum and a mixture of lime and gypsum, compared with a control treatment. Two Oxisols with different textures were used: clayey and silty. Rigid polyvinyl chloride (PVC) columns (length, $45 \mathrm{~cm}$; diam, $5 \mathrm{~cm}$ ) were used, applying 1.81 of water to each divided into four applications. Exchangeahle cations were determined in the drainage water in 4 periods and in 5 dephts of the soil columns at the end of the experiment. The results showed that losses of $\mathrm{Ca}^{2+}, \mathrm{Mg}^{2+}, \mathrm{K}^{+}$and $\mathrm{Al}^{3+}$, were higher in the treatments with gypsum and lime plus gypsum. Amendments like lime and calcium oxide did not promote significant losses of cations. Large losses occured in the silty and clayey soils in the first and second drainage times respectively. Gypsum did not modify the pII of both soils, but reduced cation amounts mainly in the clayey soil. Lime and calcium oxide raised the pII only near the application layer.
\end{abstract}

Key Words: leachining, calcium, magnesium, potassium, aluminium, gypsum, lime.

\section{INTRODUÇÃO}

Os solos ácidos apresentam baixas concentrações de bases, especialmente cálcio e magnésio, apesar da ocorrência generalizada destes elementos em diversos materiais de origem do solo. O principal processo de retirada destes elementos do perfil do solo é a lixiviação, através da água de percolação, que substitui as bases por hidrogênio $\mathrm{e}$ alumínio, intensificando a acidificação.

Para as plantas, a falta de cálcio, o aumento da acidez e o excesso de alumínio resultam em baixo crescimento do sistema radicular, com consequente exploração de pequenos volumes de solo, levando a baixa captação de nutrientes e água, tornando as culturas sujeitas a deficiências minerais e suceptíveis à déficits hídricos.

A correção da acidez e da falta de cálcio, necessária para aumentar a produtividade de solos ácidos, tem sido feita pela adição de materiais corretivos, principalmente calcários. Entretanto, como estes corretivos se solubilizam lentamente e são incorporados superficialmente, a correção normalmente se restringe à superfície, limitando o crescimento das raízes à camada de aplicação.

Nas situações onde o aprofundamento do sistema radicular da cultura é vantajoso, a lixiviação do cálcio aplicado, da superfície até camadas subsuperficiais, pode ser um fenômeno desejável. Mas, apesar de ser um processo natural na formação dos solos, a lixiviação a partir da 
adição do calcário $\in$ lenta e nem sempre resulta em aumentos significativos dos teores em profundidade. Nesse sentido, a utilização de gesso passou a ter, nos últimos anos, um interesse especial, pois, devido à solubilidade desta fonte e às reações que ocorrem no solo, a lixiviação de cálcio e de outras bases é acelerada. Assim, acredita-se que possa ter utilidade na melhoria das condições subsuperficiais, aumentando os teores em profundidade e favorecendo o aprofundamento do sistema radicular (PAVAN et al., 1982; RAIJ, 1989). A lixiviação, contudo, pode arrastar outras bases, como magnésio e potássio, para fora do alcance das raízes (PAVAN at al., 1984; QUAGGIO at al., 1982).

Este trabalho teve como objetivos acompanhar o movimento de cátions ao longo de colunas de solo, após a aplicação de calcário agrícola, gesso agrícola, calcário calcinado, e uma mistura de gesso e calcário agrícola, submetidas à percolação com água, e verificar também o efeito sobre os valores de $\mathrm{pH}$ e saturação por bases.

\section{MATERIAL E MÉTODOS}

O experimento instalado em laborat6rio contou com cinco tratamentos: tres fontes de cálcio (calcário agrícola, gesso agrícola e calcário calcinado), uma mistura das fontes gesso e calcário agrícola e uma testemunha, sem qualquer adição, todos com três repetições. As fontes de cálcio utilizadas e suas respectivas análises estão na TABELA 1.

Neste estudo, foram utilizadas amostras de terra fina seca ao ar (TFSA) de dois solos ácidos e com baixa saturação por bases: um Latossolo Vermelho escuro de textura média (LEm) e um Latossolo Vermelho Escuro de textura argilosa (LEa), cujas análises químicas se encontram na TABELA 2.

A dose de calcário agrícola adicionada foi calculada como sendo a necessidade de calagem para elevar a saturação por bases a $70 \%$, segundo a equação apresentada por RAIJ et al. (1985) e as doses das outras fontes de cálcio (gesso e calcário calcinado) foram calculadas em função da quantidade de $\mathrm{CaO}$ equivalente à aplicada como calcário. $\mathrm{Na}$ TABELA 3 são apresentadas as quantidades dos materiais e de cálcio e magnésio adicionadas por coluna em cada um dos solos.

As colunas foram montadas em tubos de PVC de $5 \mathrm{~cm}$ de diâmetro e $45 \mathrm{~cm}$ de comprimento. Cada tubo foi seccionado longitudinalmente, para facilitar a retirada do solo ao final do experimento.
As duas metades de cada coluna permaneceram unidas por fita adesiva. Na base inferior da coluna foram colocados pedriscos de quartzo e uma tela de nylon, que tiveram como finalidade sustentar o solo da coluna e permitir a passagem apenas da solução do solo. A aplicação de água às colunas foi feita com auxilio de agulhas hipodérmicas colocadas na base de copos plásticos, de modo que a água fosse adicionada lentamente no centro da coluna, evitando fluxo pelas paredes laterais. $O$ percolado foi coletado em frascos plásticos, acoplados à base da coluna (Figura 1).

As colunas de solo foram montadas com auxílio de um funil de haste longa, para que a terra fosse distribuída de maneira a mais uniforme possível. Para cada coluna foram utilizados $750 \mathrm{~g}$ de TFSA, obtendo-se uma altura de $35 \mathrm{~cm}$ e densidade do solo em torno de $1,1 \mathrm{~g} / \mathrm{cm}^{3}$. Os corretivos foram misturados com $100 \mathrm{~g}$ de solo e colocados na parte superior de cada coluna, correspondendo aos $5 \mathrm{~cm}$ superficiais. A quantidade de água adicionada a cada coluna simulou o regime hídrico típico da estação primavera-verão da região de Piracicaba. A precipitação média anual é $1245 \mathrm{~mm}$, e nos meses de setembro a fevereiro, a precipitação é de 900 $\mathrm{mm}$. Baseado nisto, o volume total de água destinado a cada coluna foi de $1,8 \mathrm{l}$, aplicados parceladamente, em quatro percolações de $450 \mathrm{ml}$, uma a cada semana.

Nos percolados, foram analisados os valores de $\mathrm{pH}$, cálcio, potássio e alumínio. Ao término do experimento, as colunas foram abertas e o solo dividido em 5 partes: $0-5 \mathrm{~cm}, 5-10 \mathrm{~cm}$, $10-15 \mathrm{~cm}, 15-25 \mathrm{~cm}$ e $25-35 \mathrm{~cm}$. Nas amostras de terra foram determinados os valores de $\mathrm{pH}$, teores trocáveis de cálcio, potássio, magnésio e alumínio, e saturação por bases: $\mathrm{pH}\left(\mathrm{CaCl}_{2}\right) ; \mathrm{P}$ (colorimetria, extração em resina); $\mathrm{Ca}, \mathrm{Mg}$ (absorção atômica, extração em resina); H+Al (tampão SMP); K (fotometria chama, extração em resina).

0 experimento foi montado utilizando-se um delineamento inteiramente casualizado, com cinco tratamentos e três repetições, sendo as médias comparadas pelo teste de Tukey a $5 \%$.

\section{RESULTADOS E DISCUSS̃̃o}

O volume de água recolhido, após cada percolação, variou pouco entre as colunas e as percolações, evidenciando que o fluxo de água foi semelhante em todas as colunas e que não houve fluxo significativo entre a parede do tubo de PVC e a coluna de solo. 
TABELA 1 - Análise química e granulométrica das fontes de cálcio aplicadas.

\begin{tabular}{lcccc}
\hline & $\mathrm{CaO}$ & $\mathrm{MgO}$ & $\mathrm{S}$ & \multirow{2}{*}{ PRNT } \\
\cline { 2 - 3 } & & $\%$ & \\
Calcário agrícola $\left(\mathrm{CaCO}_{3}\right)$ & 26,32 & 18,54 & & 88,26 \\
Gesso $\left(\mathrm{CaSO}_{4}\right)$ & 31,92 & & 17,9 & \\
Calcário calcinado $(\mathrm{CaO})$ & 31,92 & 18,14 & & 100,30 \\
\hline \hline
\end{tabular}

TABELA 2 - Análise química dos solos utilizados no experimento.

\begin{tabular}{ccccccccccc}
\hline \hline & $\mathrm{pH}$ & $\mathrm{M} . \mathrm{O}$. & $\mathrm{P}$ & $\mathrm{K}$ & $\mathrm{Ca}$ & $\mathrm{Mg}$ & $\mathrm{H}+\mathrm{Al}$ & $\mathrm{S}$ & $\mathrm{T}$ & $\mathrm{V}$ \\
\cline { 5 - 10 } & & $\%$ & $\mu \mathrm{g} / \mathrm{g}$ & & & $\mathrm{meq} / 100 \mathrm{~cm}^{3}$ & & & $\%$ \\
$\mathrm{LEa}$ & 4,1 & 3,7 & 5 & 0,38 & 1,14 & 0,44 & 10,9 & 1,96 & 12,86 & 15 \\
$\mathrm{LEm}$ & 4,1 & 1,6 & 3 & 0,11 & 0,67 & 0,23 & 4,2 & 1,01 & 5,21 & 19 \\
\hline \hline
\end{tabular}

LEa - Latossolo Vermelho-Escuro,textura argilosa

LEm - Latossolo Vermelho-Escuro,textura média

TABELA 3 - Corretivo aplicado por coluna ( $\mathrm{g}$ de material/coluna) nos diferentes tratamentos, e respectivas quantidades de cálcio e magnésio (meq/coluna).

\begin{tabular}{|c|c|c|c|c|}
\hline & & Corretivo & Cálcio & Magnésio \\
\hline & & g/coluna & & \\
\hline \multirow[t]{2}{*}{ Calcário agrícola } & LEa & 1,67 & 16 & 15 \\
\hline & LEm & 0,63 & 6 & 6 \\
\hline \multirow[t]{2}{*}{ Calcário + gesso } & LEa & $1,11+0,44$ & 15 & 10 \\
\hline & LEm & $0,42+0,17$ & 6 & 4 \\
\hline \multirow[t]{2}{*}{ Gesso } & LEa & 1,32 & 15 & - \\
\hline & LEm & 0,50 & 6 & - \\
\hline \multirow[t]{2}{*}{ Calcário calcinado } & LEa & 1,25 & 14 & 11 \\
\hline & LEm & 0,47 & 5 & 4 \\
\hline
\end{tabular}


TABELA 4 - Quantidades totais de elementos trocáveis presentes na água de percolação.

\begin{tabular}{|c|c|c|c|c|c|c|}
\hline & & $\mathrm{Ca}^{2+}$ & $\mathrm{Mg}^{2+}$ & $\mathrm{K}^{+}$ & $\mathrm{Al}^{3+}$ & $\begin{array}{c}\text { relação } \\
\mathrm{Ca} / \mathrm{Al}\left(^{*}\right)\end{array}$ \\
\hline & & & & $\mathrm{eq} / \mathrm{colu}$ & & \\
\hline \multirow[t]{2}{*}{ Calcário agrícola } & $\mathrm{LEa}$ & 11,64 & 3,61 & 10,97 & 0,26 & 0,73 \\
\hline & LEm & 4,49 & 1,54 & 1,10 & 0,36 & 0,48 \\
\hline \multirow[t]{2}{*}{ Calcário + gesso } & $\mathrm{LEa}$ & 33,55 & 10,63 & 14,01 & 0,30 & 0,94 \\
\hline & LEm & 14,57 & 3,71 & 1,29 & 0,85 & 0,61 \\
\hline \multirow[t]{2}{*}{ Gesso } & LEa & 88,09 & 19.45 & 15,98 & 0,53 & 1,06 \\
\hline & LEm & 37.64 & 2,44 & 1,45 & 1,64 & 0,72 \\
\hline \multirow[t]{2}{*}{ Calcário calcinado } & LEa & 11,65 & 3,65 & 10,87 & 0,21 & 0,76 \\
\hline & LEm & 4,72 & 1,57 & 0,88 & 0.36 & 0,49 \\
\hline \multirow[t]{2}{*}{ Testemunha } & LEa & 9.85 & 2,89 & 9,91 & 0,27 & 0,69 \\
\hline & LEm & 3,75 & 1,10 & 0,84 & 0,31 & 0,46 \\
\hline
\end{tabular}

(*) Relação $\mathrm{Ca} / \mathrm{Al}$ pela equação $1 / 2 \log \left(\mathrm{Ca}^{+2}\right)-1 / 3 \log \left(\mathrm{Al}^{+3}\right)$,SUMNER et al ,1986.

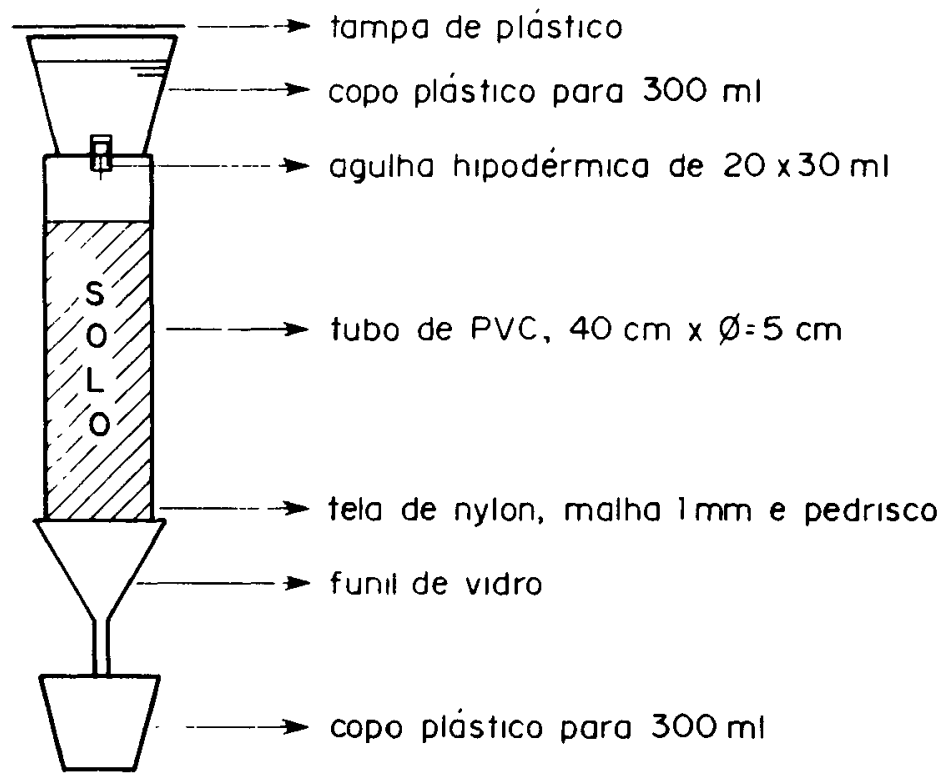

Figura 1 - Sistema utilizado para aplicação de água nas colunas e para recolhimento da solução percolada.

Sci. agric., Piracicaba. 50(1):87-98, fev./maio, 1993 
TABELA 5 - Valores de pH, saturação por bases (\%) e cálcio trocável (meq $\left./ 100 \mathrm{~cm}^{3}\right)$ no solo LEa, para cada tratamento estudado.

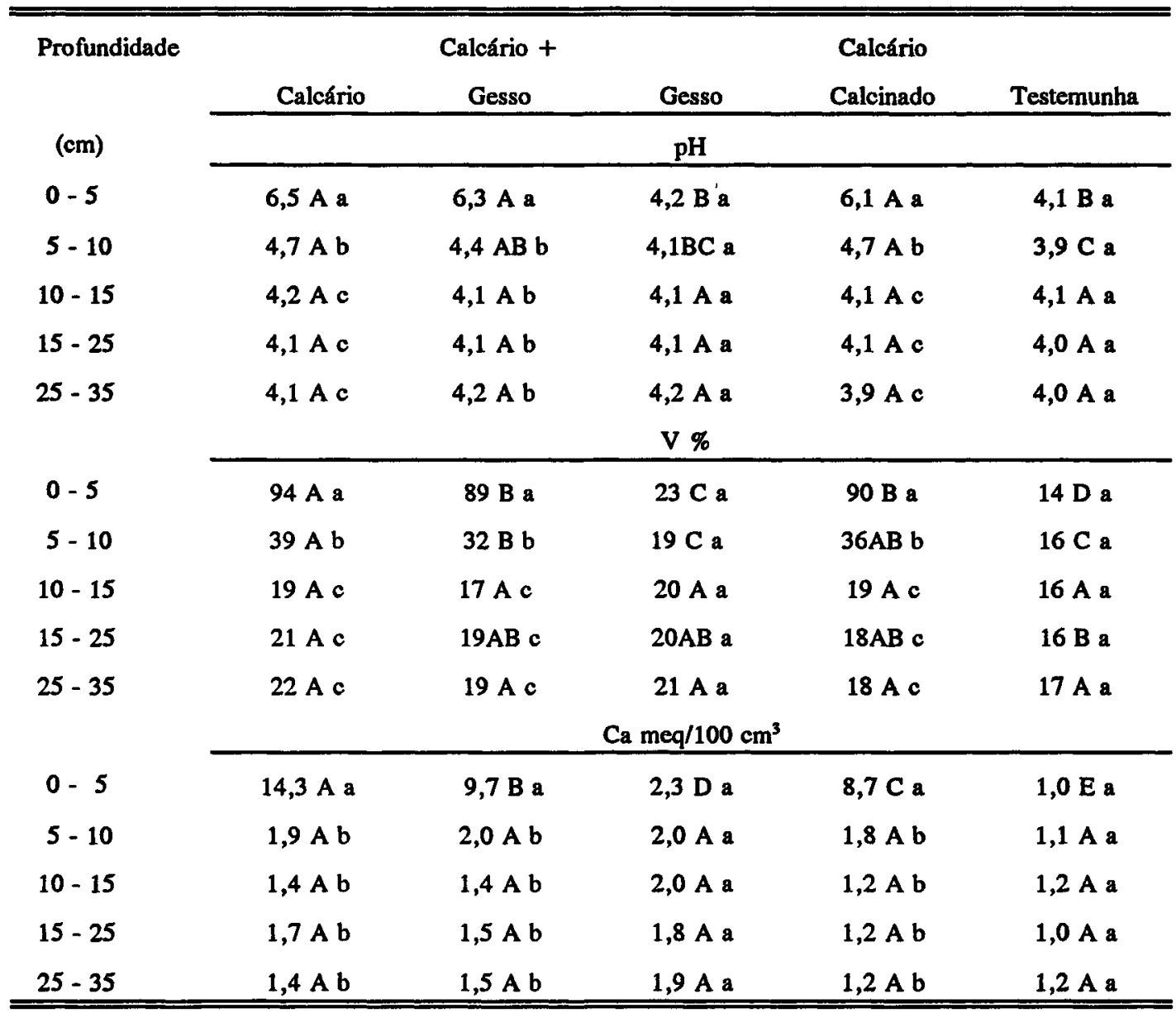

(*) Letras maiúsculas comparam tratamentos dentro de cada profundidade e letras minúsculas comparam profundidades dentro de cada tratamento. Tratamentos com letras iguais não apresentaram diferenças significativas a $5 \%$ pelo teste de Tukey.

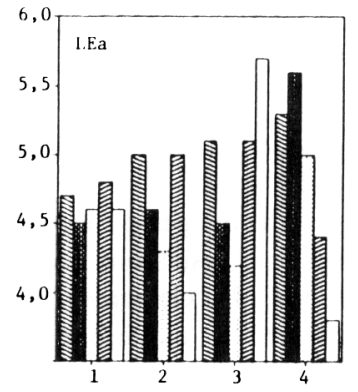

Percolações

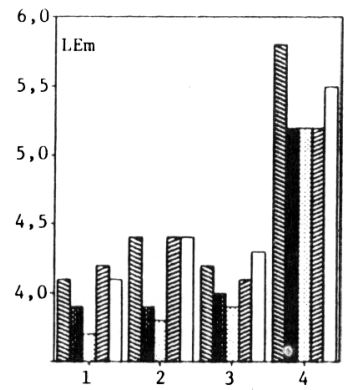

Percolaçōes
. Calcário

. Ca1c. + Gesso

․ㅏ. Gesso

. Calc.calcinado

$\square$. Testemunha

Figura 2 - Valores de pH na água das quatro-percolaç, para os cinco tratamentos, no solo LEa e no solo LEm. I DMS a $5 \%$. 
TABELA 6 - Valores de pH, saturação por bases (V) e cálcio trocável (meq $\left./ 100 \mathrm{~cm}^{3}\right)$ no solo LEm, para cada tratamento estudado.

\begin{tabular}{|c|c|c|c|c|c|}
\hline \multirow[t]{2}{*}{ Profundidade } & & Calcário & & Calcário & \\
\hline & Calcário & + Gesso & Gesso & Calcinado & Testemunha \\
\hline (cm) & \multicolumn{5}{|c|}{$\mathrm{pH}$} \\
\hline $0-5$ & $6,4 \mathrm{~A}$ a & $6,3 \mathrm{~A} \mathrm{a}$ & $4,1 \mathrm{~B} \mathrm{a}$ & $6,2 \mathrm{~A}$ a & $3,8 \mathrm{~B} \mathrm{a}$ \\
\hline $5-10$ & $4,5 \mathrm{~A} \mathrm{~b}$ & $4,4 \mathrm{~A} \mathrm{~b}$ & $3,9 \mathrm{~B} \mathrm{a}$ & $4,4 \mathrm{~A} \mathrm{~b}$ & $3,8 \mathrm{~B} \mathrm{a}$ \\
\hline $10-15$ & $4,0 \mathrm{~A} \mathrm{c}$ & $4,0 \mathrm{AC}$ & $3,9 \mathrm{~A} \mathrm{a}$ & $3,8 \mathrm{AC}$ & $3,7 \mathrm{~A} \mathrm{a}$ \\
\hline $15-25$ & $3,9 \mathrm{~A} \mathrm{c}$ & $3,9 \mathrm{~A} \mathrm{c}$ & $3,8 \mathrm{~A}$ a & 3,9 A c & $3,8 \mathrm{~A} \mathrm{a}$ \\
\hline \multirow[t]{2}{*}{$25-35$} & $3,9 \mathrm{~A} \mathrm{c}$ & 3,9 A c & $3,8 \mathrm{~A} \mathrm{a}$ & $3,8 \mathrm{~A} \mathrm{c}$ & $3,8 \mathrm{~A} \mathrm{a}$ \\
\hline & \multicolumn{5}{|c|}{ V \% } \\
\hline $0-5$ & $90 \mathrm{~A} \mathrm{a}$ & $86 \mathrm{~A} \mathrm{a}$ & $17 \mathrm{~B} \mathrm{a}$ & $85 \mathrm{~A} \mathrm{a}$ & $5 \mathrm{C} \mathrm{a}$ \\
\hline $5-10$ & $28 \mathrm{~A} \mathrm{~b}$ & $23 \mathrm{~A} \mathrm{~b}$ & $14 \mathrm{~B} \mathrm{ab}$ & $19 \mathrm{AB} \mathrm{b}$ & $5 \mathrm{Ca}$ \\
\hline $10-15$ & $5 \mathrm{Ac}$ & $7 \mathrm{~A} \mathrm{c}$ & $10 \mathrm{~A} \mathrm{ab}$ & $5 \mathrm{Ac}$ & $5 \mathrm{~A} \mathrm{a}$ \\
\hline $15-25$ & $6 \mathrm{Ac}$ & $6 \mathrm{Ac}$ & $8 \mathrm{~A} \mathrm{~b}$ & $6 \mathrm{Ac}$ & $4 \mathrm{~A} \mathrm{a}$ \\
\hline \multirow[t]{2}{*}{$25-35$} & $7 \mathrm{Ac}$ & $5 \mathrm{Ac}$ & $6 \mathrm{~A} \mathrm{~b}$ & $5 \mathrm{Ac}$ & $5 \mathrm{~A} \mathrm{a}$ \\
\hline & \multicolumn{5}{|c|}{$\mathrm{Ca} \mathrm{meq} / 100 \mathrm{~cm}^{3}$} \\
\hline $0-5$ & $4,4 \mathrm{~A} \mathrm{a}$ & $3,6 \mathrm{~B} \mathrm{a}$ & $0,7 \mathrm{C} \mathrm{a}$ & $3,5 \mathrm{~B} \mathrm{a}$ & $0,1 \mathrm{D} \mathrm{a}$ \\
\hline $5-10$ & $0,6 \mathrm{~A} \mathrm{~b}$ & $0,4 \mathrm{ABb}$ & $0,5 \mathrm{AB} a b$ & $0,4 \mathrm{AB} b$ & $0,1 \mathrm{~B} \mathrm{a}$ \\
\hline $10-15$ & $0,1 \mathrm{~A} \mathrm{C}$ & $0,2 \mathrm{~A} \mathrm{~b}$ & $0,3 \mathrm{~A} \mathrm{ab}$ & $0,1 \mathrm{~A} \mathrm{~b}$ & $0,1 \mathrm{~A} \mathrm{a}$ \\
\hline $15-25$ & $0,1 \mathrm{Ac}$ & $0,1 \mathrm{~A} \mathrm{~b}$ & $0,2 \mathrm{~A} \mathrm{~b}$ & $0,1 \mathrm{~A} \mathrm{~b}$ & $0,1 \mathrm{~A} a$ \\
\hline $25-35$ & $0,1 \mathrm{Ac}$ & $0,1 \mathrm{~A} \mathrm{~b}$ & $0,2 \mathrm{~A} \mathrm{~b}$ & $0,1 \mathrm{~A} \mathrm{~b}$ & $0,1 \mathrm{~A} \mathrm{a}$ \\
\hline
\end{tabular}

(*) Letras maiúsculas comparam tratamentos dentro de cada profundidade, e letras minúsculas comparam profundidades dentro de cada tratamento. Tratamentos com letras iguais não apresentaram diferenças significativas a $5 \%$ pelo teste de Tukey.

A TABELA 4 apresenta as quantidades totais (soma das quatro percolações) dos elementos trocáveis $\left(\mathrm{Ca}^{2+}, \mathrm{Mg}^{2+}, \mathrm{K}^{+}, \mathrm{Al}^{3+}\right)$, perdidos por percolação durante o decorrer do experimento. Verifica-se que as perdas de cálcio, magnésio e potássio foram sempre superiores no solo argiloso (LEa), provavelmente em função da maior fertilidade inicial deste solo $e$ das maiores quantidades adicionadas no caso do $\mathrm{Ca}^{2+}$ e do $\mathrm{Mg}^{2+}$. No solo de textura média, os totais perdidos foram mais baixos, mas o efeito dos tratamentos nos dois solos foi semelhante.

Os tratamentos com gesso e calcário mais gesso foram aqueles que resultaram em maiores quantidades de todos os elementos na água pcrcolada. Os tratamentos calcário agrícola e calcário calcinado apresentaram valores próximos aos do tratamento testemunha, inclusive para os elementos cálcio e magnćsio, que não foram adicionados na testemunha. Destacam-se as grandes

Sci. agric., Piracicaba. 50(1):87-98, fev./maio, 1993 
TABELA 7 - Valores de magnésio, potássio e alumínio trocáveis (meq/100cm), encontrados no solo LEa, para cada tratamento estudado.

\begin{tabular}{|c|c|c|c|c|c|}
\hline \multirow[t]{2}{*}{ Profundidade } & \multicolumn{3}{|c|}{ Calcário + } & \multicolumn{2}{|l|}{ Calcário } \\
\hline & Calcário & Gesso & Gesso & Calcinado & Testemunha \\
\hline$(\mathrm{cm})$ & \multicolumn{5}{|c|}{$\mathrm{Mg}$ meq $/ 100 \mathrm{~cm}^{3}$} \\
\hline $0-5$ & $11,3 \mathrm{~A} \mathrm{a}$ & $6,3 \mathrm{~A} \mathrm{~b}$ & $0,1 \mathrm{C} \mathrm{a}$ & $6,2 \mathrm{~B} \mathrm{a}$ & $0,4 \mathrm{Ca}$ \\
\hline $5-10$ & $1,7 \mathrm{~A} \mathrm{~b}$ & $1,4 \mathrm{AB} \mathrm{ab}$ & $0,1 \mathrm{C} \mathrm{a}$ & $1,7 \mathrm{~A} \mathrm{~b}$ & $0,4 \mathrm{BC}$ a \\
\hline $10-15$ & $0,5 \mathrm{~A} \mathrm{c}$ & $0,4 \mathrm{~A} \mathrm{c}$ & $0,1 \mathrm{~A} \mathrm{a}$ & $0,5 \mathrm{Ac}$ & $0,5 \mathrm{~A} \mathrm{a}$ \\
\hline $15-25$ & $0,5 \mathrm{~A} \mathrm{c}$ & $0,4 \mathrm{Abc}$ & $0,2 \mathrm{~A}$ a & $0,6 \mathrm{Ac}$ & $0,4 \mathrm{~A} \mathrm{a}$ \\
\hline \multirow[t]{2}{*}{$25-35$} & $0,6 \mathrm{~A} \mathrm{c}$ & $0,5 \mathrm{~A} \mathrm{bc}$ & $0,2 \mathrm{~A} \mathrm{a}$ & $0,6 \mathrm{Ac}$ & $0,5 \mathrm{~A} \mathrm{a}$ \\
\hline & \multicolumn{5}{|c|}{$\mathrm{K} \mathrm{meq} / 100 \mathrm{~cm}^{3}$} \\
\hline $0-5$ & $0,09 \mathrm{Cd}$ & $0,11 \mathrm{BC} b$ & $0,12 \mathrm{BC} \mathrm{c}$ & $0,15 \mathrm{BC} \mathrm{d}$ & $0,21 \mathrm{Ac}$ \\
\hline $5-10$ & $0,16 \mathrm{BC} c$ & $0,12 \mathrm{Cb}$ & $0,13 \mathrm{Cc}$ & $0,20 \mathrm{Cc}$ & $0,25 \mathrm{~A} \mathrm{bc}$ \\
\hline $10-15$ & $0,22 \mathrm{~B} \mathrm{~b}$ & $0,13 \mathrm{C} \mathrm{b}$ & $0,15 \mathrm{C}$ bc & $0,26 \mathrm{C} \mathrm{bc}$ & $0,28 \mathrm{~A} \mathrm{ab}$ \\
\hline $15-25$ & $0,30 \mathrm{~A} \mathrm{a}$ & $0,22 \mathrm{BC}$ a & $0,19 \mathrm{Cb}$ & $0,25 \mathrm{C} \mathrm{b}$ & $0,30 \mathrm{~A} \mathrm{ab}$ \\
\hline \multirow[t]{2}{*}{$25-35$} & $0,34 \mathrm{~A} \mathrm{a}$ & $0,27 \mathrm{C} \mathrm{a}$ & $0,25 \mathrm{~B} \mathrm{a}$ & $0,34 \mathrm{~B} \mathrm{a}$ & $0,33 \mathrm{~A} \mathrm{a}$ \\
\hline & \multicolumn{5}{|c|}{$\mathrm{Al} \mathrm{meq} / 100 \mathrm{~cm}^{3}$} \\
\hline $0-5$ & $0,1 \mathrm{C} \mathrm{c}$ & $0,1 \mathrm{C} \mathrm{c}$ & $1,0 \mathrm{~B} \mathrm{~b}$ & $0,1 \mathrm{Cc}$ & $1,6 \mathrm{~A} \mathrm{a}$ \\
\hline $5-10$ & $0,3 \mathrm{D} \mathrm{c}$ & $0,7 \mathrm{C} \mathrm{b}$ & $1,2 \mathrm{~B} \mathrm{ab}$ & $0,6 \mathrm{C} \mathrm{b}$ & $1,6 \mathrm{~A} \mathrm{a}$ \\
\hline $10-15$ & $0,9 \mathrm{~B} \mathrm{~b}$ & $1,0 \mathrm{~B} \mathrm{a}$ & $1,4 \mathrm{~A} \mathrm{a}$ & $1,4 \mathrm{~A}$ a & $1,4 \mathrm{~A} a b$ \\
\hline $15-25$ & $1,3 \mathrm{~A} \mathrm{a}$ & $1,2 \mathrm{~A}$ a & $1,4 \mathrm{~A} \mathrm{a}$ & $1,5 \mathrm{~A} \mathrm{a}$ & $1,4 \mathrm{~A}$ ab \\
\hline $25-35$ & $1,1 \mathrm{~B} \mathrm{ab}$ & $1,1 \mathrm{~B} \mathrm{a}$ & $1,4 \mathrm{~A} \mathrm{a}$ & $1,4 \mathrm{~A} \mathrm{a}$ & $1,1 \mathrm{AB} \mathrm{b}$ \\
\hline
\end{tabular}

(*) Letras maiúsculas comparam tratamentos dentro de cada profundidade, e letras minúsculas comparam profundidades dentro de cada tratamento. Tratamentos com letras iguais não apresentaram diferenças significativas a $5 \%$ pelo teste de Tukey.

quantidades de $\mathrm{Mg}$ e $\mathrm{K}$ perdidas na percolação, principalmente porque são dois nutrientes não adicionados quando se aplica gesso. Em termos de percentagem relativa à testemunha, a aplicação de gesso resultou em perdas $570 \%$ maiores de $\mathrm{Mg}$ no LEa e $120 \%$ maiores no LEm, enquanto a mistura gesso mais calcário resultou, em média nos dois solos, em perdas $250 \%$ maiores.

O potássio apresenta valores semelhantes nos dois solos em termos percentuais, aos tratamentos gesso e calcário mais gesso, perdendo, respectivamente, $65 \%$ e $50 \%$ a mais em relação à testemunha. Essas perdas são menos acentuadas que as de $\mathrm{Mg}$, porque esse elemento se movimenta com maior facilidade no perfil e mesmo no tratamento testemunha, há grande transporte desse elemento. A TABELA 4 mostra, também, a relação entre $\mathrm{Ca}^{2+} \mathrm{e} \mathrm{Al}{ }^{3+}$ através da equação $1 / 2 \log \left(\mathrm{Ca}^{2+}\right)$ $-1 / 3 \log \left(\mathrm{Al}^{3+}\right)$. Nota-se um aumento dos valores calculados nos dois tratamentos em que foi aplicado 
TABELA 8 - Valores de magnésio, potássio e alumínio trocáveis $\left(\mathrm{meq} / 100 \mathrm{~cm}^{3}\right)$ encontrados no solo $\mathrm{LEm}$, para cada tratamento estudado.

\begin{tabular}{|c|c|c|c|c|c|}
\hline \multirow[t]{2}{*}{ Profundidade } & & Calcário + & & Calcário & \\
\hline & Calcário & Gesso & Gesso & Calcinado & Testemunha \\
\hline$(\mathrm{cm})$ & \multicolumn{5}{|c|}{$\mathrm{Mg} \mathrm{meq} / 100 \mathrm{~cm}^{3}$} \\
\hline $0-5$ & $3,7 \mathrm{~A} \mathrm{a}$ & $2,4 \mathrm{~B} \mathrm{a}$ & $0,1 \mathrm{C} \mathrm{a}$ & $2,4 \mathrm{~B} \mathrm{a}$ & $0,1 \mathrm{C} \mathrm{a}$ \\
\hline $5-10$ & $0,6 \mathrm{~A} \mathrm{~b}$ & $0,4 \mathrm{AB} \mathrm{b}$ & $0.1 \mathrm{~B} \mathrm{a}$ & $0,4 \mathrm{AB} b$ & $0,1 \mathrm{~B} \mathrm{a}$ \\
\hline $10-15$ & $0,1 \mathrm{~A} \mathrm{c}$ & $0,1 \mathrm{~A} \mathrm{~b}$ & $0,1 \mathrm{~A} \mathrm{a}$ & $0,1 \mathrm{~A} \mathrm{~b}$ & $0,1 \mathrm{~A} \mathrm{a}$ \\
\hline $15-25$ & $0,1 \mathrm{Ac}$ & $0,1 \mathrm{~A} \mathrm{~b}$ & $0,1 \mathrm{~A}$ a & $0,1 \mathrm{~A} \mathrm{~b}$ & $0,1 \mathrm{~A} \mathrm{a}$ \\
\hline \multirow[t]{2}{*}{$25-35$} & $0,1 \mathrm{Ac}$ & $0,1 \mathrm{~A} \mathrm{~b}$ & $0,1 \mathrm{~A} \mathrm{a}$ & $0,1 \mathrm{~A} \mathrm{~b}$ & $0,1 \mathrm{~A} \mathrm{a}$ \\
\hline & \multicolumn{5}{|c|}{$\mathrm{K} \mathrm{meq} / 100 \mathrm{~cm}^{3}$} \\
\hline $0-5$ & 0,02 B C & $0,04 \mathrm{~B} \mathrm{a}$ & $0,02 \mathrm{~B} \mathrm{a}$ & $0,02 \mathrm{AB}$ a & $0,03 \mathrm{~A} \mathrm{a}$ \\
\hline $5-10$ & $0,04 \mathrm{~A} \mathrm{ab}$ & $0,03 \mathrm{~B} \mathrm{a}$ & $0,02 \mathrm{~B} \mathrm{a}$ & $0,03 \mathrm{~B} \mathrm{a}$ & $0,03 \mathrm{AB} a b$ \\
\hline $10-15$ & $0,03 \mathrm{~A} b c$ & $0,03 \mathrm{~A} \mathrm{a}$ & $0,03 \mathrm{~A} \mathrm{a}$ & $0,03 \mathrm{~A} \mathrm{a}$ & $0,04 \mathrm{~A} \mathrm{a}$ \\
\hline $15-25$ & $0,04 \mathrm{~A}$ ab & $0,03 \mathrm{AB} \mathrm{a}$ & $0,03 \mathrm{AB}$ a & $0,03 \mathrm{~A}$ a & $0,02 \mathrm{~B} \mathrm{~b}$ \\
\hline \multirow[t]{2}{*}{$25-35$} & $0,05 \mathrm{~A} \mathrm{a}$ & $0,03 \mathrm{~B} \mathrm{a}$ & $0,03 \mathrm{~B} \mathrm{a}$ & $0,03 \mathrm{~B} \mathrm{a}$ & $0,03 \mathrm{~B} \mathrm{ab}$ \\
\hline & \multicolumn{5}{|c|}{$\mathrm{Al} \mathrm{meq} / 100 \mathrm{~cm}^{3}$} \\
\hline $0-5$ & $0,1 \mathrm{Cc}$ & $0,1 \mathrm{C} \mathrm{c}$ & $0,8 \mathrm{~B} \mathrm{a}$ & $0,1 \mathrm{C} \mathrm{c}$ & $1,1 \mathrm{~A} \mathrm{a}$ \\
\hline $5-10$ & $0,4 \mathrm{C} \mathrm{b}$ & $0,5 \mathrm{Cb}$ & $0,9 \mathrm{~B} \mathrm{a}$ & $0,6 \mathrm{C} \mathrm{b}$ & $1,1 \mathrm{~A} \mathrm{a}$ \\
\hline $10-15$ & $1,0 \mathrm{~B} \mathrm{a}$ & $0,9 \mathrm{~B} \mathrm{a}$ & $0,9 \mathrm{~B} \mathrm{a}$ & $1,1 \mathrm{AB}$ a & $1,2 \mathrm{~A} \mathrm{a}$ \\
\hline $15-25$ & $1.0 \mathrm{~A} \mathrm{a}$ & $1,0 \mathrm{~A} \mathrm{a}$ & $0,9 \mathrm{~A} \mathrm{a}$ & $1,1 \mathrm{~A}$ a & $1,1 \mathrm{~A} \mathrm{a}$ \\
\hline $25-35$ & $1,1 \mathrm{~A} \mathrm{a}$ & $1,1 \mathrm{~A} \mathrm{a}$ & $1,0 \mathrm{~A} \mathrm{a}$ & $1,1 \mathrm{~A} \mathrm{a}$ & $1,1 \mathrm{~A} \mathrm{a}$ \\
\hline
\end{tabular}

(*) Letras manúsculas comparam tratamentos dentro de cada profundidade, e letras minúsculas comparam profundidades dentro de cada tratamento. Tratamentos com letras iguais não apresentaram diferenças significativas a $5 \%$ pclo teste de Tukey.

o gesso, oncordando com resultados obtidos por SUMNER et al. (1986).

Os valores obtidos para o $\mathrm{pH}$ e os teores de elementos perdidos em cada percolação para os solos LEa e LEm encontram-se, respectivamente, nas Figuras 2, 3 e 4 . Uma análise geral das quantidades perdidas mostra que no solo LEm os maiores valores estão principalmente na primeira percolação, caindo acentuadamente nas percolações relacionado com a menor retenção da água $\mathrm{e}$ maior movimentação da solução do solo, no solo de textura mais grosseira.
Nota-se ainda, que nos dois tratamentos que reccberam gesso as perdas ocorreram na forma de pulso acentuado, na primeira percolação no solo LEm e na segunda percolação no solo LEa, para todos os elementos.

\section{pII e Saturação por bases.}

Da observação das TABELAS 5 e 6 , verifica-se que a aplicação de calcário agrícola, calcário + gesso e calcário calcinado promoveu significativa elevação de $\mathrm{pH}$ apenas na camada de 

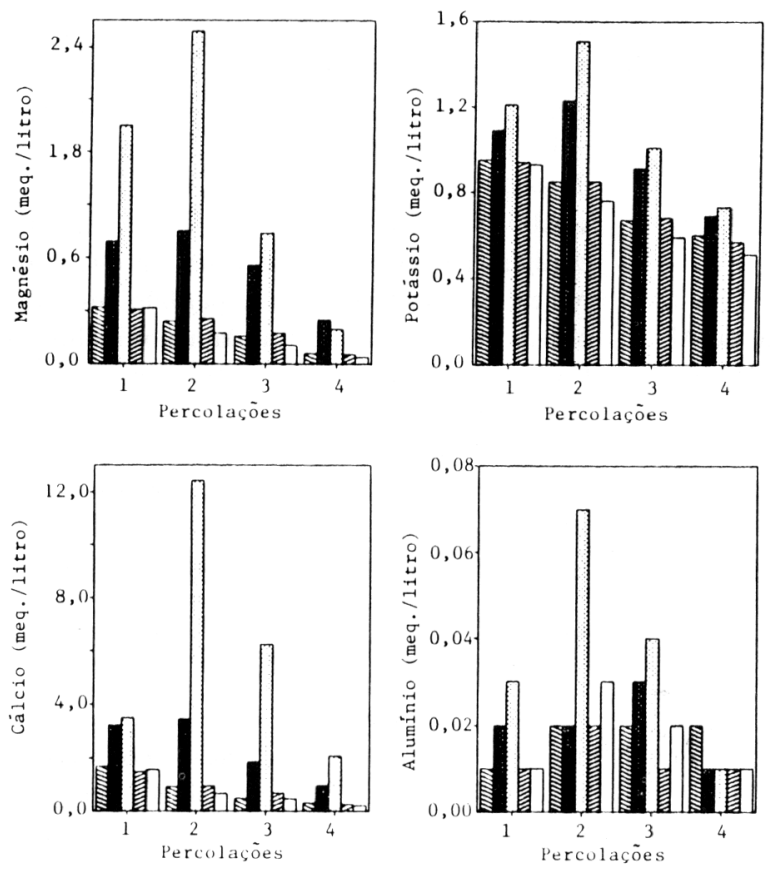

Salcário

. Ca1.+Gesso

‥ Gesso

Calc.calcinado

$\square$. Testemunha

Figura 3 - Valores de cátions trocávcis, em meq/litro, na água das quatro percolações para os cinco tratamentos, no solo LEa. I DMS a $5 \%$.
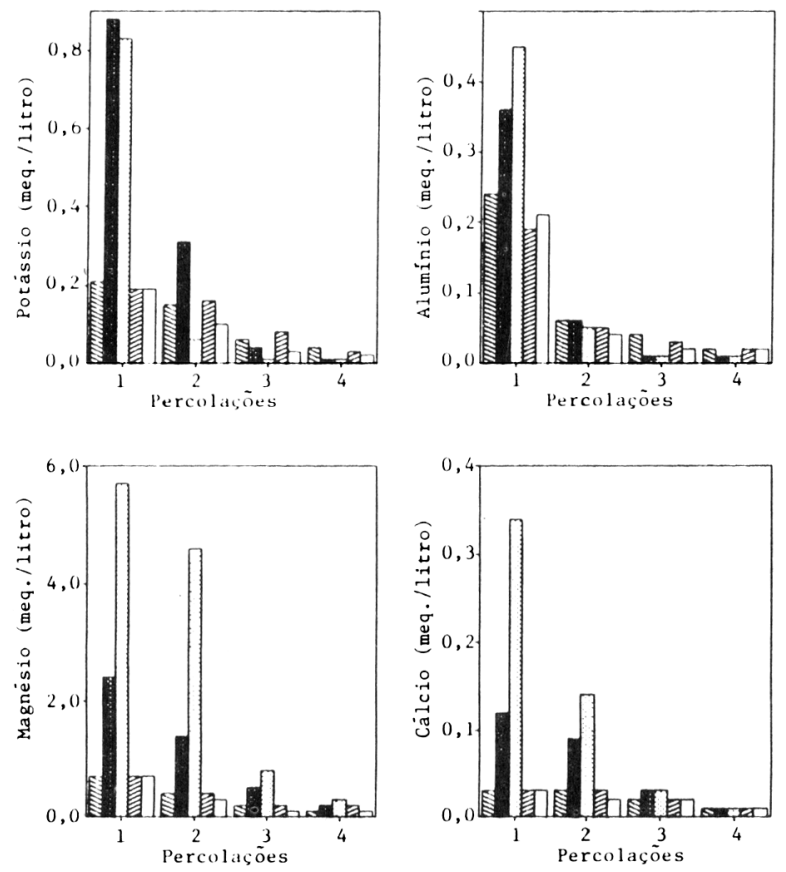

Salcārio

.Ca1. + Gesso

․ㅏ. Gesso

Calc.calcinado

$\square$. Testemunha

Figura 4 - Valores de cátions trocáveis, em meq/litro, na água das quatro percolações para os cinco tratamentos, no solo LEm. I DMS a 5\%. 
0 a $5 \mathrm{~cm}$, sendo que pequeno aumento foi ainda observado na profundidade 5 a $10 \mathrm{~cm}$. Abaixo dessa profundidade, nenhum dos tratamentos alterou o $\mathrm{pH}$ dos solos, no período estudado. A aplicação de gesso não promoveu nenhuma alteração no pH dos solos, concordando com as observações de PAVAN et al. (1984).

Doses elevadas de gesso podem diminuir o pH do solo, por efeito salino ou hidrólise de $\mathrm{Al}$ (ALVA et al., 1990). Analisando o pH das soluções percoladas (Figura 2), nota-se que os tratamentos com gesso proporcionaram os índices de $\mathrm{pH}$ mais baixos, possivelmente pelo efeito salino de maior lixiviação de bases, enquanto que - tratamento com calcário elevou o $\mathrm{pH}$ das soluções percoladas. Estes efeitos foram observados nos dois solos estudados, entretanto o $\mathrm{pH}$ da solução no solo argiloso apresentou muita variação entre percolações. Dessa forma, o pH da solução não apresentou boa correlação com as perdas por lixiviação.

Todos os tratamentos aumentaram a saturação por bases (V\%) apenas na camada 0 a 10 $\mathrm{cm}$ e, em algumas situações, o valor de V\% foi superior a $70 \%$ na camada 0 a $5 \mathrm{~cm}$. Estes dois resultados foram provocados pela incorporação superficial dos matcriais adicionados e mostram pouca mobilidade das bases adicionadas.

\section{Cálcio}

Nos tratamentos com calcário agrícola e na testemunha, no solo $\mathrm{LEa}$, as maiores perdas de cálcio na água ocorreram na primeıra percolação, enquanto que nos tratamentos que continham gesso, a maior concentração de cálcı ocorreu na segunda percolação.

Em todas as percolações, maiores quantidades de cálcıo foram determinadas no tratamento com gesso, seguido do tratamento gesso + calcário, evidenciando a solubilidade deste material no solo Pelos dados obtidos pode-se dizer que não houve lıxıvıação do cálcio adicionado via calcário, pois, nestes tratamentos, as quantidades determinadas foram iguais a testemunha.

Os dados obtidos com o LEm revelam a mesma tendência entre tratamentos, só que as maiores perdas ocorrem já na primeira percolação (Figura 4), sendo acentuada a redução dos valores na terceira e quarta percolações.

Grande quantidade de cálcio permaneceu nas camadas de 0 a $5 \mathrm{~cm}$ de profundidade, quando se adicionou calcário agrícola, calcário + gesso e calcário calcinado. Nas camadas subsequentes, as quantidades de cálcio foram bem menores, não havendo diferença em relação a testemunha, indicando que houve pouca mobilidade do cálcio desses materiais, possivelmente devido a baixa solubilização (TABELAS 5 e 6). As quantidades perdidas nos percolados confirmam que realmente pouco $\mathrm{Ca}$ foi solubilizado e perdido por lixiviação nesses tratamentos. Apesar da maior mobilidade do $\mathrm{Ca}$ nos tratamentos com gesso, os teores deste elemento no solo, em profundidade, não foram significativamente diferentes da testemunha, contrariando os resultados obtidos por SOUZA \& RITCHEY (1986) que encontraram distribuição no solo mais uniforme com aplicação de gesso.

\section{Magnésio}

Os tratamentos com gesso apresentaram maiores perdas por lixiviação no $\mathrm{LEa}$, numa situação muito semelhante ao cálcio. Pela Figura 3, vê-se que o gesso promoveu maiores perdas, sendo este magnésio proveniente do solo, visto que não foi adicionado no tratamento gesso nenhuma fonte deste cátion. Portanto a aplicação de gesso sozinho pode levar a uma perda de magnésio para camadas mais profundas do solo, tornando-se um problema se colocar o elemento fora do alcance das raízes

No LEm as perdas no percolado foram altas na primeira passagem de água, caındo acentuadamente nas demais (Figura 4). Isto pode ser consequência da baixa concentração exıstente no solo e da sua alta drenagem, de forma que na última percolação as quantidades medidas foram muito baixas em todos os tratamentos. Neste solo as perdas também foram maiores nos tratamentos com gesso.

Na segunda percolação o tratamento gesso + calcário perdeu mais magnésio que o tratamento gesso sozinho devido ao magnésio presente no corretivo. PAVAN et al. (1984) e ALVA et al. (1991a) observaram substanciais perdas de $\mathrm{Mg}$ trocável no solo tratado com gesso. Embora não tenha sido observada diferença significativa nos teores de magnésio no solo entre os tratamentos com gesso e testemunha (TABELAS 7 e 8), os dados mostram que houve diminuição nos teores de magnésio principalmente no solo argiloso. Essas diferenças não foram significativas do ponto de vista estatístico principalmente porque os tratamentos com calcário tinhara adição de magnésio, elevando o teor deste elemento. Os tratamentos contendo calcário e calcário calcinado, 
promoveram elevação no teor de $\mathrm{Mg}$ nas camadas 0-10 cm, por serem fontes de $\mathrm{Mg}$ e provavelmente pela elevação do $\mathrm{pH}$ e praticamente não provocaram perdas nos lixiviados. A lixiviação de $\mathrm{Mg}$ não ocasionou acúmulo desse elemento nas camadas inferiores, sendo arrastado para além da profundidade de $35 \mathrm{~cm}$.

\section{Potássio}

No LEa as perdas de potássio foram sempre maiores no tratamento com gesso, seguido do tratamento gesso + calcário (Figura 3). Os demais tratamentos perderam mais que a testemunha somente nas duas últimas percolações. No solo de textura média as perdas foram mais expressivas na primeira percolação, caindo acentuadamente nas seguintes, devido à baixa concentração do potássio e à alta drenagem deste solo (Figura 4). Da mesma forma que o magnésio, a lixiviação do potássio, especialmente em solos pobres, pode ser grave se atingir profundidades fora do alcance das raízes (REEVE \& SUMNER, 1972 e QUAGGIO et al., 1982).

Não se observaram diferenças entre os teores de $\mathrm{K}$ nas diversas profundidades analisadas para o solo LEm (TABELA 8), devido principalmente ao baixo teor inicial de $\mathrm{K}$ nesse solo. Embora a bxiviação de $\mathrm{K}$ nesse solo tenha sido menor que $0,5 \mathrm{meq} / 100 \mathrm{ml}$ (Figura 4), ela ocorreu logo na primeira lixiviação, tendo sido o tratamento com gesso o que mais carreou $\mathrm{K}$ nos percolados. Para o LEa, houve movimento descendente de $\mathrm{K}$ no solo, sendo que nos tratamentos com calcário $\mathrm{e}$ calcário calcinado, houve decréscimo na camada superficial e acréscimos nas camadas subsequentes. O gesso nesse solo proporcionou sensíveis perdas de K por lixiviação, evidenciada na Figura 3. Essas perdas foram responsáveis por teores de $\mathrm{K}$ menores no solo tratado com gesso, em relação à testemunha. Foi significativo o aumento de $\mathrm{K}$ em profundidade em todos os tratamentos, inclusive na testemunha, indicando a alta mobilidade do elemento nesses solos.

\section{Alumínio}

Nos dois solos, o gesso promoveu as maiores perdas de alumínio, seguido do gesso + calcário, sendo as diferenças mais acentuadas na primeira e segunda percolações (Figuras 3 e 4). As maiores perdas ocorreram no solo arenoso, devido a maior quantidade de alumínio presente.
Em todos os tratamentos houve diminuição do $\mathrm{Al}$ trocável apenas nas camadas de 0-5 cm para o solo $\mathrm{LEm}$ e $0-10 \mathrm{~cm}$ para $\mathrm{LEa}$ (TABELAS 7 e 8). As aplicações de gesso são citadas frequentemente como eficientes na diminuição do $\mathrm{Al}$ trocável e na saturação de $\mathrm{Al}$, mesmo em camadas mais profundas (RITCHEY et al., 1980 e ALVA et al., 1991-b). Mas, neste experimento, o gesso teve pouca eficiência na diminuição do Al trocável em profundidade. Embora, como se observa nas Figuras 3 e 4, o gesso tenha proporcionado as maiores perdas de $\mathrm{Al}$ nos percolados, as quantidades foram muito pequenas, próximas a $0,08 \mathrm{meq} / 100 \mathrm{ml}$ no $\mathrm{LEa}$ e $0,4 \mathrm{meq} / 100 \mathrm{ml}$ no LEm. PAVAN et al. (1984) verificaram a redução do Al trocável até $1 \mathrm{~m}$ de profundidade em colunas de solo tratadas com gesso, sendo que não houve perda significativa de $\mathrm{Al}$ por lixiviação. Grande parte do $\mathrm{Al}$ trocável passou a formas não solúveis em água e $\mathrm{KCl}$ no trabalho desses autores.

As reações do $\mathrm{SO}^{2 \cdot}$ com o $\mathrm{Al}^{3+}$, quer sejam por formação de complexos solúveis e insolúveis, ou pela formação de hidróxidos de alumínio, influenciam a disponibilidade do $\mathrm{Al}$ para as plantas e consequentemente, diminuem o efeito tóxico para as raízes. Vários complexos que se formam entre o $\mathrm{SO}_{4}^{2-} \mathrm{e} O \mathrm{Al}^{3+}$, reduzem a atividade do cátion e portanto a determinação da concentração total do $\mathrm{Al}^{3+}$ fornece poucas indicações sobre seu comportamento no ambiente (PAVAN, 1986). Nesse sentido, trabalhos recentes procuram analisar não apenas a concentração de $\mathrm{Al}^{3+}$, como também avaliar as espécies iônicas que se formam no solo.

\section{CONCLUSÕES}

- Os tratamentos gesso e gesso mais calcário promoveram significativas perdas de $\mathrm{Ca}^{2+}, \mathrm{Mg}^{2+}$, $\mathrm{K}^{+}$e $\mathrm{Al}^{\mathrm{s}+}$ nas soluções lixiviadas dos dois solos estudados, sendo que as maiores perdas ocorreram na primeira percolação para o solo de textura média e na segunda percolação para o solo argiloso;

- o gesso não alterou o $\mathrm{pH}$ do solo, mas reduziu os teores de $\mathrm{K}^{+}, \mathrm{Mg}^{2+}$ e $\mathrm{Al}^{\text {s+ }}$ no Latossolo Vermelho escuro argiloso;

- aplicações de calcário dolomítico e calcário calcinado não promoveram perdas significativas de cátions por lixivição e mantiveram os cátions na camada incorporada. 


\section{AGRADECIMENTOS}

Os autores agradecem ao Prof. Dr. RONALDO IVAN SILVEIRA, do Departamento de Ciência do Solo da ESALQ-USP, pelo empréstimo dos materiais utilizados, auxílio e orientaçã̀o nas análises químicas do experimento.

\section{REFERÊNCIAS BIBLIOGRÁFICAS}

ALVA, A.K.; GASCHO, G.J.; GUANG, Y. Soil solution and extractable calcium in gypsum-amended coastal plain soils used for peanut culture. Communications in Soil Science and Plant Analysis, New York, v.22, p.99-116, 1991a.

ALVA, A.K.; SUMNER,M.E.; MILLER, W.P. Reactions of gypsum or phosphogypsum in highly weathered acid subsoils. Soil Sciece Society of America Journal, Madison, v.54, p.993-998, 1990.

ALVA, A.K.; SUMNER, M.E.; MILLER, W.P. Chemical effects of repeated equilibrations of variable-charge soils with phosphogypsum solution. Soil Science Society of American Journal, Madison, v.55, p.357-361, $1991 \mathrm{~b}$.

PAVAN, M.A. Comportamento do gesso nos solos ácidos das regiōes tropicais e subtropicais. Informações Agronômicas, Piracicaba, v.35, p.1-2, 1986.

PAVAN, M.A.; BINGHAM, F.T.; PRATT, P.F. Toxicity of aluminium to coffee in ultisols and oxisols amended with $\mathrm{CaCO}_{3}, \mathrm{MgCO}_{3}$, and $\mathrm{CaSO}_{4} .2 \mathrm{H}_{2} \mathrm{O}$. Soil Science Society of America Journal, Madison, v.46. p.1201-1207, 1982 .

PAVAN, M.A.; BINGHAM, F.T.; PRATT, P.F. Redistribution of exchangeable calcium, magnesium and aluminium following lime or gypsum applications to a Brazilian oxisol. Soil Science Society of America Journal, Madison, v.48, p.33-38, 1984.

QUAGGIO, J.A.; DECHEN, A.R.; RAIJ, B. van. Éeitos da aplicação de calcário e gesso sobre a produção de amendoim e lixiviação de bases no solo. Revista Brasileira de Ciência do Solo, Campinas, v.6, p.189-194, 1982.
RAIJ, B.van. Melhoria do ambiente radicular do subsolo. In: SIMPÓSIO AVANÇADO DE SOLO E NUTRIÇÃO DE PLANTAS, 2., Piracicaba, 1989. Anais... Campinas : Fundaçāo Cargill, p.117-148.

RAIJ, B.van; SILVA, N.M.; BATAGLIA, O.C.; QUAGGIO, J.A.; HIROCE, R.; CANTARELLA, H.; BELLINAZZIJR. R.; DECHEN, A.R.; TRANI, P.E. Recomendaçōes de adubação e calagem para 0 Estado de São Paulo. Campinas, Instituto Agronômico, 1985. 107p. (IAC. Boletim Técnico, 100).

REEVE, N.G.; SUMNER, M.E. Amelioration of subsoil acidity in Natal oxisols by leaching of surface-applied amendments. Agrochemophysica, Pretoria, v.4, p. 1-6, 1972.

RITCHEY, K.D.; SOUZA, D.M.G.; LOBATO, E.; CORREA, O. Calcium leaching to increase rooting depth in a Brazilian savannah Oxisol. Agronomy Journal, Madison, v.72, p.40-44, 1980.

SOUZA, D.M.G.; RITCHEY, K.D. Correção de acidez de subsuperfície: uso de gesso no solo de cerrado. In: SIMPÓSIO AVANÇADO DE SOLOS E NUTRIÇÃO DE PLANTAS, 2., Piracicaba, 1989. Campinas : Fundação Cargill, 1989. p.91-113.

SUMNER, M E.; SHAHANDEH, H.; BOUTON, J.; HAMMEL, J. Amelioration of an acid soil profile through deep liming and surface application os gypsum. Soil Science Society of America Journal, Madison, v 50, p.1254-1258, 1986.

Trabalho entregue para publicação em 19.02.92

Trabalho aprovado para publicação em 08.06.92 